\section{Are We Thinking Too Straight? Why We Need More LGBTQ+ Studies in India: A Perspective}

\section{DOI: 10.52629/jamsa.v9i1.234}

Abstract Despite India's antiquity recognizing all types of queer sexualities, there is still much stigma and taboo that surrounds the Indian LGBTQ+ community. This stigmatization can be reflected in the scarcity of data and scientific literature that focuses on the community, and can also be reflected in the numerous health disparities still faced by the community.

Medical curricula are almost devoid of information related to the LGBTQ+ community, and studies have shown that many doctors refuse to accept LGBTQ+ patients, while other doctors are unable to provide proper treatment, despite wishing to do so, due to lack of knowledge and skill. These can be seen as factors causing various health disparities, such as higher risks of mental health disorders and heart diseases, among others.

Encouraging more research could be beneficial, at multiple levels. With increased research on LGBTQ+ centric topics, more data can be collected on the issues faced by the community, which in turn can be used to educate both the society and the researcher. Gaps in the education and healthcare systems can also be identified and therefore rectified.

While the Indian LGBTQ+ community and the issues faced by them are gaining recognition, more must be done to ensure equitable healthcare for all, and encouraging scientific research is a significant way to do so.

Keywords India, LGBTQ+, healthcare, health disparities, research, stigma
Anjali Mediboina', 2

1 Academic Delegate, Asian Medical Studen Association

2 Medical Student, Alluri Sita Ramaraju Academy of Medical Sciences, Eluru, India

\footnotetext{
Correspondence to:

Anjali Mediboina

Medical Student, Alluri Sita

Ramaraju Academy of

Medical Sciences, Eluru, India

anjalimediboina@gmail.com
} 


\section{Introduction}

LGBTQ+ stands for Lesbian, Gay, Bisexual, Transgender, and Queer. The "+" signifies that one acronym cannot capture everyone's experience of their gender identity or expression and/or sexual orientation. Queer is a word that has been used historically as a slur or insult against members of the LGBTQ+ community but has been reclaimed by the community in recent years, to be an umbrella term for someone who is not heterosexual and/or cisgender?

Being the land of ancient civilizations, India's history is rich and diverse, as reflected in its religions, ethnicities, customs, and social structures. Religion has played a large part in shaping lifestyles, art, and literature; with religious diversity and tolerance being established in the country by law and custom ${ }^{2}$. According to the 2011 Census, Hinduism is the most widely practiced religion in India, followed by the traditions of Sikhism, Islam, Christianity, Jainism, and Buddhism ${ }^{3}$.

Indian antiquity has always recognized, and accommodated, third gender and queer sexualities ${ }^{4}$. There are countless examples one could cite; In Hinduism, gender-fluidity is a common theme- the God Vishnu becomes damsel Mohini, Lord Shiva becomes Ardhanareshwara or half-woman. Transgenders are also seen in the great Hindu epic, MahabharataArjuna, and Shikhandi. Jain scriptures recognize that the body can be male (purusha), female (stri), or queer (napunsaka). In Buddhist literature, greater importance is given to behavior, rather than biological markings, so we hear of men who have sex with men or women who behave like men ${ }^{4}$.

Despite this richly queer history, the taboo that surrounds the Indian LGBTQ+ community is staggering. Extreme social rejection is one of the main reasons for the existing stigma. In India, society plays a significant role in an individual's life, and social acceptance is a must. Thus, the fear of being rejected from society causes LGBTQ+ individuals to remain closeted and also prevents people from openly expressing their support for the community, as well.

In a study conducted by Srivastava et al. ${ }^{5}$ participants have cited homosexuality as being unsupported by law or against the law, as a reason for stigma. Laws, such as the former Section 377 of the Indian Penal Code, which deemed "carnal intercourse against the order of nature ${ }^{6 "}$. Under this law, people engaging in oral and anal intercourse were prosecuted, and the law also criminalized homosexuality and sexual minorities. While India has taken a step in the right direction with the decriminalization of Section 377 in 2018, same-sex couples still cannot be legally married, nor can they adopt a child. Conversion therapy is not yet explicitly banned by law ${ }^{7}$ and LGBTQ+ people are banned from openly serving in the military $^{8}$. Other participants viewed homosexuality as taboo, merely because they were taught to perceive it as an "unnatural act". 


\section{The Consequences}

Due to the stigma and taboo, there are numerous consequences faced by the community, such as family- enacted violence and lack of family acceptance, the pressure to marry, violence from peers and partners ${ }^{5}$. Chakrapani et al, found that victimization and violence contribute to internalized homonegativity and/or depression, which in turn contribute to alcohol use, and these are sequentially or concurrently associated with higher HIV risk ${ }^{9}$.

The major consequence is the health disparities faced by the community. The discrimination at places of healthcare has led to major health disparities, including, but not limited to, areas of behavioral health, physical health, and access to care $^{10}$. There is a higher risk to certain health conditions, such as:

- Higher rates of sexually transmitted infections- LGBTQ+ individuals are at higher risk of infections of HIV, HPV, and other STIs such as chlamydia, gonorrhea, and syphilis.

- Higher rates of breast and cervical cancer- Sexual minority women underutilize cervical cancer screening services, with screening rates estimated to be between 43 $71 \%$ compared to $73 \%$ in the general female population ${ }^{17}$.

- Higher odds of obesity and eating disorders- Various studies have shown that bisexual and lesbian women are more likely to be overweight or obese than women who identify as heterosexual and that eating disorders and body image disorders may be more common among gay and bisexual men than heterosexual men ${ }^{12}$.

- Higher risks of heart diseaselesbian, gay, and bisexual adults have a higher risk of heart disease and other cardiac problems than heterosexual adults ${ }^{13}$.

Another major health disparity faced by the community is the negative effects on mental health. Many LGBTQ+ individuals face extreme parental rejection, which in turn increase their stigma experiences and the lack of support from their parents makes them vulnerable to mental health disorders. A study published in 2009 found that gay, lesbian, and bisexual young adults who experienced rejection from families were 8 times more likely to have tried to attempt suicide, 6 times more likely to report high levels of depression, and 3 times more likely to use illegal drugs $^{14}$.

There is a lack of knowledge regarding the community, which can also be viewed as a direct result of the taboo surrounding it. Researchers have found that over half of medical school curricula include no information about gay and lesbian people ${ }^{15}$. Even now, the only information about the LGBTQ+ community in Indian medical textbooks is the vague definitions of "Sodomy" and "Tribadism", all of which are described under the chapter "Sexual Offences" in Forensic Medicine ${ }^{16}$. Almost all medical textbooks are still gender 
conforming and have no information about gender- affirming surgeries and gender dysphoria. Ultimately, physicians make heteronormative assumptions about their LGBTQ+ patients, which lead to poor patient-physician relationship and provision of insufficient or careless treatment ${ }^{17}$.

This lack of knowledge is also a reason for the existence of discrimination and stigma. A study carried out by Sharma et al. ${ }^{18}$ found that many doctors were not comfortable touching transgender patients and tried to have minimal contact with them, would try to avoid providing transgender patients with necessary treatment, and even purposefully prescribe the wrong medication, because of pre conceived notions about the patient's sexual health. On the other hand, lack of knowledge also prevents those doctors who wish to provide proper care, from being in a position to do so ${ }^{19}$.

There is also a dearth in Indian scientific literature that has investigated issues related to the LGBTQ+ community; Wandrekar et al. conducted a systematic review of existing literature from 20092019 on the Mental Health of Indian LGBTQ+ individuals, where it was found that most studies had MSM (men who have sex with men), as participants, followed by transwomen, and then lesbian and bisexual women. Only 4 studies included transmen, and 2 studies included intersex, genderqueer, nonbinary, and genderfluid individuals, and individuals identifying as pansexual and queer. Only one study described the experiences of a person who identified as asexual ${ }^{20}$.

\section{The Solution: Educational Reforms and Encourage More Research}

Healthcare and research go hand in hand; research is essential to advance knowledge for the good of society; to improve the health of people worldwide, and to find better ways to treat and prevent disease ${ }^{21}$. Research also provides valuable insight regarding interventions and solutions that can be taken.

More scientific literature on the LGBTQ+ community will not only help close the health gap, but can also help break the stigma. By encouraging more studies that focus on the LGBTQ+ community, knowledge will be gained by both the community and the researcher. They also promote discussion and help normalize these "taboo" topics. Studies such as those conducted by Hardacker et al. ${ }^{22}$, have proved that research can bring about a change in an individual's attitude and that education is the key to solving stigma-related issues.

Universities can encourage more research by granting scholarships for Short Term Studentships, exclusively for LGBTQ+ related research, similar to those conducted by the ICMR. This will create both awareness and opportunities for students.

During the COVID-19 lockdown, various online workshops and webinars were conducted via the Asian Medical Students Association (AMSA) India on topics such 
as "Medical Care for LGBTQIA+ Youth", "Sex and Gender Sensitive Medicine" and "Sex Education". Encouraging such workshops, both online and offline, targeting people in both medical and non-medical professions, is also another measure to help increase awareness and eliminate stigma.

Aside from research, there must be reforms in education, at all levels. At a primary level, the school curricula should also be modified to be more LGBTQ+ inclusive. Shaping the minds of the young ones is essential, and thus, children should be taught from a young age not to use derogatory terms, and should also be taught about the negative effects of bullying on the victims. Education laws should be updated, to ensure proper reporting of any and all bullying incidents.

In medical education, competency training should be a must for all medical and para-medical staff and students. Medical textbooks should be modified and updated to include more LGBTQ+ related information, and remove any insensitive terminology. Integration of LGBTQ+ related health training in the medical curriculum can minimize any implicit bias based on sexuality, as demonstrated by various studies, such as those conducted by Salkind et al. ${ }^{23}$.

\section{Conclusion}

While India has shown progress by taking steps, such as striking down Section 377 in 2018, there is still much bias and discrimination against LGBTQ+ individuals.
This bias can be reflected in the dearth of data and scientific literature on the issues faced by the community, and the presence of innumerable health disparities faced by the community.

Research is essential in raising awareness and eradicating taboos and prejudice against the community. It can promote healthy discussions about sexual identity and sexuality, and in the process, help bridge the health gaps faced by the LGBTQ+ community. By encouraging research, one can educate society and the researcher, thus helping break the stigma.

Research is also vital to bring about reforms in education. By conducting more studies, the gaps in education can be identified and therefore rectified, and ensure an LGBTQ+ friendly learning environment at all educational levels.

In order to ensure equity in health, there is an urgent need to understand the health status and needs of sexual minorities and there is a requisite for more data on the disparities faced by the community in the Indian healthcare sector. Promoting more scientific studies is therefore essential to understand these health disparities.

Thus, while the LGBTQ+ community and the issues faced by them are gradually gaining recognition, there is much that needs to be done to make this awareness rapid and widespread. Healthcare and education need to be made more inclusive, and encouraging LGBTQ+ centric research and literature is one of the best ways to do so. 


\section{References}

1. LGBTQ+ Community - Partners for Peace [Internet]. Partnersforpeaceme.org. 2020 [cited 28 March 2021]. Available from: https://www.partnersforpeaceme.org/abou t-abuse/is-this-

abuse/lgbtcommunity/\#: :text=Partners\%2 Ofor\%20Peace\%20advocates\%20are,the $\% 2$ Odelivery\%20of\%20our\%20services.

2. Basu DD, Manohar VR, Banerjee BP, Khan SA. Introduction to the Constitution of India. Wadhwa; 2001 [cited 9 April 2021].

3. Religion Data - Population of Hindu / Muslim / Sikh / Christian - Census 2011 India [Internet]. Census2011.co.in. 2011 [cited 9 April 2021]. Available from: https://www.census2011.co.in/religion.php

4. Patnaik D. 713 Devdutt Pattanaik, The LGBTQ movement in India [Internet]. Indiaseminar.com. 2019 [cited 6 January 2021]. Available from: http://indiaseminar.com/2019/713/713_devdutt_pattan aik.htm\#: :text=Queer\%20examples\%20inc lude\%20Shiva\%20who,forms\%20of\%20the \%20same\%20God.

5. Srivastava S, Singh P. Psychosocial roots of stigma of homosexuality and its impact on the lives of sexual minorities in India. Open Journal of Social Sciences. 2015;3(08):128. Available from: https://www.scirp.org/pdf/JSS_20150821102 20314.pdf

6. Code IP, Scale P. Government of India. New Delhi, Orient Law House. 1860. Availble from:

https://lawcommissionofindia.nic.in/report s/report202.pdf

7. Indian Association of Clinical Psychologists. Official Standing of IACP regarding 'conversion therapy' and approach towards lesbian, gay, bisexual, and transgender persons (LGBTQIA+). [Internet]. 2020. Available from: http://iacp.in/wpcontent/uploads/2020/05/IACP-Positionstatement-on-treatment-of-LGBTQ.pdf
8. Pathak MK, Rai S, Upadhyay M. Social, Medical And Human Rights Issues Related To Transgenders In India. Journal of Punjab Academy of Forensic Medicine \& Toxicology. 2019 Jan 1;19(1). Available from: https://www.indianjournals.com/ijor.aspx?t arget=ijor:jpafmat\&volume=19\&issue $=1 \&$ arti cle=editorial

9. Chakrapani V, Kaur M, Newman P, Mittal S, Kumar R. Syndemics and HIV-related sexual risk among men who have sex with men in India: Influences of stigma and resilience [Internet]. 2018 [cited 6 January 2021]. Available from: https://www.ncbi.nlm.nih.gov/pmc/articles /PMC6430415/

10. LGBT Health Disparities / Cigna [Internet]. Cigna.com. 2017 [cited 6 January 2021]. Available from: https://www.cigna.com/individualsfamilies/health-wellness/lgbt-disparities

11. Baptiste-Roberts K, Oranuba E, Werts N, Edwards LV. Addressing health care disparities among sexual minorities. Obstetrics and Gynecology Clinics. $2017 \mathrm{Mar}$ 1;44(1):71-80. Available from: https://www.ncbi.nlm.nih.gov/pmc/articles /PMC5444328/\#R62

12. Gillespie C. 6 Major Health Disparities Affecting the LGBTQ+ Community [Internet]. Health.com. 2020 [cited 30 March 2021]. Available from: https://www.health.com/mind-body/lgbtqhealth-disparities

13. Saxena A, Rubens M, Das S, Rajan T, Grandhi G, Arias L, Nasir K, Veledar E. Abstract P001: LGB Health Disparities: Examining the Status of Ideal Cardiovascular Health From the 2011-2012 NHANES Survey. Circulation. 2018 Mar 20;137(suppl_1):AP001-. Available from:

https://www.ahajournals.org/doi/abs/10.1161 /circ.137.suppl_1.p001

14. Ryan C, Huebner D, Diaz RM, Sanchez J. Family rejection as a predictor of negative 
health outcomes in white and Latino lesbian, gay, and bisexual young adults. Pediatrics. 2009 Jan 1;123(1):346-52.

15. Krehely J. How to Close the LGBT Health Disparities Gap - Center for American Progress [Internet]. Center for American Progress. 2009 [cited 6 January 2021]. Available from: https://www.americanprogress.org/issues/l gbtq-rights/reports/2009/12/21/7048/howto-close-the-lgbt-health-disparities-gap/

16. Reddy K. Essentials of forensic medicine and toxicology. [Place of publication not identified]: JAYPEE Brothers MEDICAL P; 2017.

17. Lapinski J, Sexton P, Baker L. Acceptance of Lesbian, Gay, Bisexual, and Transgender Patients, Attitudes About Their Treatment, and Related Medical Knowledge Among Osteopathic Medical Students [Internet]. 2014 [cited 6 January 2021]. Available from: https://jaoa.org/article.aspx?articleid $=2094$ 779

18. Sharma R, Mishra P. Transgender: health and rights. European Journal of Pharmaceutical and Medical Research. 2020:570-9.

19. McPhail D, Rountree-James M, Whetter I. Addressing gaps in physician knowledge regarding transgender health and healthcare through medical education. Canadian medical education journal. 2016 Oct;7(2):e70.

20. Wandrekar J, Nigudkar A. What Do We Know About LGBTQIA+ Mental Health in India? A Review of Research From 2009 to 2019 - Jagruti R. Wandrekar, Advaita S. Nigudkar, 2020 [Internet]. SAGE Journals. 2020 [cited 6 January 2021]. Available from: https://journals.sagepub.com/doi/full/10.117 7/2631831820918129

21. What is the purpose of medical research? [Internet]. The Lancet. 2013 [cited 6 January 2021].

Available

from: https://www.thelancet.com/journals/lancet /article/PIIS0140-6736(13)60149-

$\mathrm{X} /$ fulltext\#articleInformation

22. Hardacker C, Rubinstein B, Hotton A, Houlberg M. Adding silver to the rainbow: the development of the nurses' health education about LGBT elders (HEALE) cultural competency curriculum [Internet]. 2014 [cited 6 January 2021]. Available from: https://pubmed.ncbi.nlm.nih.gov/23869475 /

23. Salkind J, Gishen F, Drage G, Kavanagh J, Potts HW. LGBT+ health teaching within the undergraduate medical curriculum. International journal of environmental research and public health. 2019 Jan;16(13):2305. Available from: https://www.ncbi.nlm.nih.gov/pmc/articles /PMC6651354/ 